\title{
Editorial
}

\section{Towards new horizons}

My previous Editorial [1], described the plans for a series of urgently needed changes to our journal with respect to the volume, circulation and contents. The changes were coupled to the expiration of the present agreement with Springer-Verlag, which was due in December 1991. It is with considerable pride and pleasure that I can inform you that these plans, which were discussed at the General Assembly of the EASD in 1990, have been realized and that a new agreement has been signed with Springer. As described by our President in the News Section, which appears for the first time in this issue, the new terms were obtained only after considerable analyses of competing offers from other publishers and negotiations with Springer. It is also clear, however, that the resulting agreement satisfies a number of conditions put forward by the Executive Committee of our Association.

The first condition to be fulfilled is a radical increase in the circulation by the implementation of mandatory subscription for all members of the EASD. Secondly, there will be more space for publication, up to 1200 pages per year, which will mean an increase of $25 \%$ compared to 1991 . Thirdly, a new channel for communication between the EASD membership and its Council and Study Groups has been created as the EASD News Section, which will appear in each issue for EASD members and, hopefully, will serve as an efficient forum for diffusion of information from the various activities happening in the Association. The News Section will be edited by the Executive Director of the EASD and will be published separately from the scientific part of the journal. In addition, EASD members under 35 years of age will receive the journal with their membership fee and a solidarity fund to support members from countries with non-convertible currencies and/or poor library facilities has also been implemented. I anticipate that these changes will be to the benefit of our readers who as from now include all the members of the EASD.

During the last two years we have faced an increasing inflow of manuscripts to Diabetologia and, as this editorial is being written, the prediction for 1991 is for a record high of over 500. Due to the limited space for publication the acceptance rate for 1990 fell to only $24 \%$ and many good manuscripts could therefore not be printed. For 1991, with the increase in publication space, we calculate the acceptance rate to be around $30 \%$. Provided we con- tinue to receive a high proportion of good manuscripts, the rate of acceptance for 1992 should be raised to around $35 \%$. It should be pointed out, though, that we have no plans to lower the scientific standard of the journal by accepting manuscripts of less than top quality and therefore only time will tell if the available number of pages can be filled.

The net result of all these changes is that as from 1992, Diabetologia will become a larger, more widely read journal. The work-load on the editorial staff will increase but seeing the journal grow and thrive is a great stimulation which fills us with enthusiasm. The fact that Diabetologia remains one of the most cited journals in diabetology is a challenge to continue our efforts in improving the quality of the journal.

Looking a little further into the future it can of course be questioned if it is a wise decision to increase the circulation and volume of Diabetologia at a time when the days of conventionally printed and published journals may be numbered. The time may not be too far away when expensively produced scientific journals, in which each paper is read by relatively few people, may lose the competition with computer-conveyed information, which can be selected by the subscriber to fit only her or his personal tastes and interests.

However, these techniques are still under development and our goal remains to publish as much clinical and experimental work on all aspects of diabetes research as we are able provided it has scientific merit and represents important advance in knowledge. Inherent in this goal is the striving towards the widest possible diffusion of this new knowledge to the benefit of the scientists, the clinicians and, last but not least, the patients. The editorial staff of Diabetologia is proud and happy to participate in this endevour and would like to wish our readers, authors and referees a very Happy New Year.

Claes Hellerström

Uppsala, 1 January 1992

\section{References}

1. Hellerström C (1990) A letter from the Editor. Diabetologia 34: 1 